\title{
SupportScreen: A Model for Improving Patient Outcomes
}

\author{
Matthew Loscalzo, MSW; ${ }^{a}$ Karen Clark, MS; Jeff Dillehunt; ${ }^{b}$ Redmond Rinehart; ${ }^{\mathrm{b}}$ Rex Strowbridge; ${ }^{\mathrm{b}}$ and \\ Daniel Smith; ${ }^{\mathrm{b}}$ Duarte, California
}

Key Words

Biopsychosocial, screening, technology, personalized medicine, clinical efficiency

\begin{abstract}
As demands on physician time mount, and patients and families increasingly expect accommodation and understanding of their specific, personal situations, care providers must boost efficiency and minimize the expense of their clinic processes and draw on connections with community resources. Third-party payors may also expect that the biopsychosocial needs of patients and families be addressed as an essential part of cancer care. Quality of care, cost, patient satisfaction, adherence to treatment, safety, and allocation of limited resources are all related to the identification and effective management of the psychosocial elements of cancer care. Experts suggest that health care has lagged far behind other industries in using technology to improve efficiency, and slow adoption of this technology means that critical information about the biopsychosocial needs of patients fails to reach the right professionals in a timely way. Systematic and automated screening can promote physician control in managing time, the efficiency of the clinical encounter, and rapid triage to other professionals and community resources. (JNCCN 2010;8:496-504)
\end{abstract}

\section{Identifying Distress to Enhance Whole-Patient-Centered Care}

As many as $47 \%$ of cancer patients have been shown to experience emotional distress at the level of a diag-

From the aSheri \& Les Biller Patient and Family Resource Center Department of Supportive Care Medicine, and 'Department of Information Technology Services, City of Hope, Duarte, California. Submitted October 23, 2009; accepted for publication

December 16, 2009.

Mr. Loscalzo and Ms. Clark have disclosed that they have a financial interest in the sale of this licensed technology via City of Hope. Mr. Dillehunt, Mr. Rinehart, Mr. Strowbridge, and Mr. Smith have disclosed that they have no financial interests, arrangements, or affiliations with the manufacturers of any products discussed in this article or their competitors.

Correspondence: Matthew Loscalzo, MSW, Sheri \& Les Biller Patient and Family Resource Center, Department of Supportive Care

Medicine, City of Hope, 1500 East Duarte Road, Main Medical Bldg

Suite Y-1, Duarte, CA 91010-3000. E-mail: Mloscalzo@COH.org nosable psychiatric disorder. ${ }^{1,2}$ However, patients have distress that is caused by more than psychiatric problems. Informational, educational, social, psychological, spiritual, financial, and practical problems, in the absence of mental illness, also can cause disabling distress. The psychosocial impact of physical symptoms, alone or in combination with issues such as depression, anxiety, and financial vulnerability, also influence the ability to cope and manage the many demands endemic to the cancer experience. Identifying and managing the biopsychosocial domains may seem to be a time-consuming and daunting task for physicians when they have increasingly less time to spend with patients. This is true in both large academic cancer centers and small community practices.

Several studies show the financial-offsetting advantages of addressing biopsychosocial issues, despite the effort and cost of establishing an automated screening/ triage system. ${ }^{3-5}$ These include cost benefits to hospitals providing psychosocial care, ${ }^{3}$ and the potential for psychological distress screening to predict and intervene in patient treatment noncompliance, appointmentbreaking, ${ }^{4}$ and clinical trial discontinuation. ${ }^{5}$

The early identification of biopsychosocial problems is essential to relieve distress, prevent crises, and minimize system disruption. Potential barriers preventing identification of these problems include stigma, lack of a common language, health care professional avoidance of emotional content, lack of professional training to acquire this information, and the belief that these problems are less important than physical care. In addition to the barriers endemic to identification and communication of biopsychosocial vulnerabilities, system-based barriers also exist, such as the lack of a standardized comprehensive approach to the identification of biopsychosocial problems. Supported by the literature, ${ }^{6-8}$ the $\mathrm{NCCN}^{9}$ and the Institute of Medicine (IOM) 2007 
Report (Cancer Care for the Whole Patient: Meeting Psychosocial Health Needs) ${ }^{10}$ recommend psychosocial distress screening for all patients to address problems before a crisis develops and necessitates higher levels of intervention. An increasing number of screening instruments are now in use, such as the Distress Thermometer ${ }^{9}$ and the Edmonton Symptom Assessment Scale. ${ }^{11}$

However, patients may still express considerable hesitation to discuss distress based on social stigma and fear associated with cancer. Although the stigma related to the vulnerabilities of cancer is decreasing, the emotional, psychosocial, psychiatric, and financial problems endemic to cancer have been much more resistant to change. Physicians and nurses, however, can play a major role in encouraging patients to voice illness-related concerns. Instituting biopsychosocial screening for all patients early in the clinical encounter can communicate an openness and sense of hope that patients and families can manage any barriers related to their medical care. In the authors' experience, patients do not expect physicians and nurses to fix all illness-related problems, but do expect them to be knowledgeable about mental health and other essential resources in the community. An efficient and reliable way to identify the essential needs and barriers for patients is through biopsychosocial screening., ${ }^{9,10}$ The authors have taken this process a step further by automating biopsychosocial screening through the use of touch-screen technology. ${ }^{12}$

\section{SupportScreen}

Improved Patient Outcomes "At Your Fingertips" The authors' team developed a new touch screen automated program called SupportScreen (www. supportscreen.com), based on more than 15 years of screening experience in academic cancer centers and a small community hospital. SupportScreen is an inexpensive, patient-friendly automated process that identifies, triages, and provides educational information in real time. This program covers the entire process of biopsychosocial screening, from initiation of patient responses to the generation of referrals and provision of educational information. The program is designed to facilitate patient, physician, and specialist communication and to maximize the effectiveness of clinical encounters and overall cancer care. SupportScreen was also designed to run on simple network systems and to be adapted to a variety of settings, including small clinical practices.

\section{From Paper to Automation: Increased Efficiency and Communication}

Historically, biopsychosocial screening was performed with paper and pencil, but paper screening tools can be time-consuming for staff to review, analyze, and use to make referrals, limiting their use. In addition, information on paper was not consistently delivered to the physician in time for discussion during the clinical encounter. The authors and others ${ }^{3,11}$ have shown that automation can decrease resource intensity while creating systems that provide enhanced timely communication, tailored interventions, clinical summaries, and real-time triage. In the longer term, automation can also create a database that is immediately updated and available. This article discusses the SupportScreen tool and the specific benefits it, and other programs like it, can bring to patients and their families, physicians, and clinical settings, as well as how City of Hope integrated it into their systems.

\section{Benefits to Patients and Families, Physicians, and Clinical Settings}

Physician time is increasingly consumed with seeing more patients because of decreased reimbursement and with administrative demands, such as authorizations and use review. As a result, physicians spend less time with each individual patient. Research has shown, ${ }^{13}$ however, that the quality of the clinical encounter, not just the time spent with the patient, is associated with better health outcomes and higher patient satisfaction. Automated screening programs such as SupportScreen have the potential to optimize the time physicians spend with patients.

Patients experience clinical encounters as stressful and emotionally charged. Within this context, patient-physician communication is primarily focused on disease-directed information at the expense of critical biopsychosocial domains. Programs like SupportScreen can alert both patients and physicians to barriers to medical care. It can provide a common language, a normalization of problems, and a decrease in concerns about stigma. For the health care team (physicians, nurses, support staff) the information is neatly organized and documented electronically, and provides cues for referrals to other services in real time. 
Loscalzo et al.

Table 1 Potential Benefits of SupportScreen

\begin{tabular}{|c|c|c|}
\hline For Patients and Families & For Physicians and Staff & For Clinical Settings/Institutions \\
\hline $\begin{array}{l}\text { - Provides a user-friendly electronic } \\
\text { interface } \\
\text { - De-stigmatizes requests for help } \\
\text { - Teaches patients about common } \\
\text { problems } \\
\text { - Gives patients a voice and } \\
\text { common language to partner } \\
\text { with their health care providers } \\
\text { - Identifies barriers to medical care } \\
\text { - Gives sense of control, direction, } \\
\text { and plan of action } \\
\text { - Tailors education materials } \\
\text { printed out in real time } \\
\text { - Enhances communication and } \\
\text { trust with health care team } \\
\text { - Prioritizes immediate needs } \\
\text { - Accelerates timely referrals to } \\
\text { supportive services } \\
\text { - Tailors support services } \\
\text { - Raises the expectations of } \\
\text { psychosocial services being } \\
\text { provided } \\
\text { - Improves continuity of care }\end{array}$ & $\begin{array}{l}\text { - Increases control over the clinical encounter } \\
\text { - Maximizes efficiency of the time spent } \\
\text { taking a history and physical } \\
\text { - Reduces time needed to anticipate and } \\
\text { manage barriers to medical care } \\
\text { - Avoids distraction on areas outside of } \\
\text { medical expertise } \\
\text { - Assures communication among } \\
\text { multispecialists } \\
\text { - Enhances medical charting through } \\
\text { automated links to ICD-9 codes } \\
\text { - Screens all patients quickly and efficiently as } \\
\text { standard of clinical care } \\
\text { - Enhances communication and trust with } \\
\text { patient } \\
\text { - Identifies high-risk patients for disruption of } \\
\text { clinic processes } \\
\text { - Identifies high-risk patients for lack of } \\
\text { compliance } \\
\text { - Automates, summarizes, and prioritizes } \\
\text { problems } \\
\text { - Streamlines triage and referral to } \\
\text { appropriate resources } \\
\text { - Reduces data entry and verification burden } \\
\text { - Provides invaluable data for grants, } \\
\text { publications, and program development } \\
\text { - Exports easily to commonly used software } \\
\text { - Creates more efficient data interpretation }\end{array}$ & $\begin{array}{l}\text { - Raises the standard of clinical care } \\
\text { - Increases patient satisfaction } \\
\text { - Minimizes disruption of clinic } \\
\text { processes and systems } \\
\text { - Increases patient safety } \\
\text { - Decreases clinic no-shows } \\
\text { - Automates identification and triage } \\
\text { to other institutional services } \\
\text { - Increases revenue through } \\
\text { automated links to ICD-9 codes } \\
\text { - Maximizes internal resources } \\
\text { - Creates linkages to external } \\
\text { community resources } \\
\text { - Reduces administrative costs } \\
\text { - Increases staff efficiency } \\
\text { - Increases staff satisfaction and } \\
\text { retention } \\
\text { - Serves as model for other } \\
\text { institutions } \\
\text { - Enhances competitiveness in the } \\
\text { market place } \\
\text { - Creates funding opportunities }\end{array}$ \\
\hline
\end{tabular}

The benefits patients and families, physicians, nurses, and other health care professionals may derive from SupportScreen are shown in Table 1. Although this program focuses on patients with cancer, the implications for other chronic illnesses are transparent. People dealing with serious illness must be able to effectively communicate with their health care team to adapt to the reality of illness, make difficult decisions, identify barriers to care, and actively participate in rehabilitation and palliation. Programs like SupportScreen can become the foundation for an evolving partnership through systematic electronic communication among patients, their primary health care team, and the specialists involved in their medical care.

\section{Automating Processes in the Clinic}

SupportScreen is an automated touch-screen system (See Figure 1) that identifies, summarizes, and triages patient biopsychosocial problems in real time. It can facilitate patient, physician, and specialist com- munication through an electronic interface built to be user-friendly and compatible with most standard patient software systems. SupportScreen also provides customized reports for clinical, educational, and research purposes. Figure 2 outlines the screening process in the clinic, and Table 2 details the specific features as they relate to professional users.

\section{Patient-Friendly Content}

The content of SupportScreen is based on screening data (both paper-based ${ }^{14-16}$ and electronic ${ }^{11}$ ) from more than 10,000 cancer patients. The present 53-question screening instrument uses simple language to address the most common physical, practical, social, psychological, nutritional, physical rehabilitation, and spiritual problems encountered by patients with cancer. ${ }^{17}$ Depending on the focus and resources of the clinic setting, items can be modified, added, or deleted. The language is patient-friendly and has been tested in various clinical settings to en- 


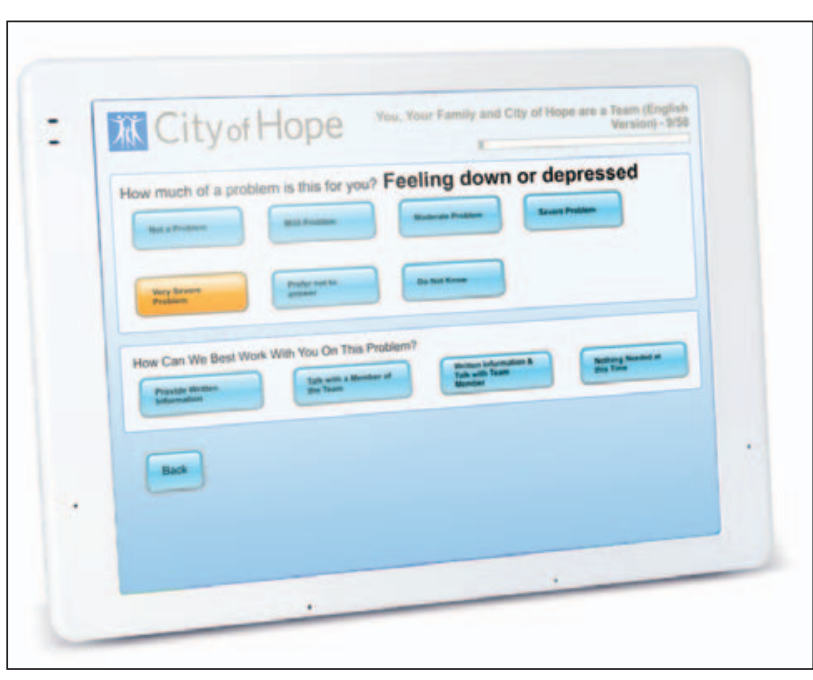

Figure 1 SupportScreen Tablet.

sure that the content is easily understood and relates directly to the question being asked. According to the Flesch-Kincaid readability test, the content of SupportScreen items scores at a fourth-grade reading level. ${ }^{18}$ Patients are given the opportunity to rate how much of a problem each of the 53 items is on a 5-point scale from Not a Problem to Very Severe Problem (Table 3). In addition, patients are asked if they are requesting to Talk with a Member of the Team, to have the team Provide Written Information, or Nothing Needed at this Time. SupportScreen is presently available in English and Spanish and takes approximately 15 to 20 minutes to complete.

To minimize patient and staff burden, demographic variables are prepopulated in the screening database from the medical record system to avoid a need to repeat basic patient information. To help the patient understand the context and value of the screening process, a standard introductory letter from the patient's physician appears on the first screen of SupportScreen. The letter includes a picture of the physician or team, and explains how the screening process can enable the patient to partner with the health care team and that the information can be helpful in planning care. Finally, the introductory letter guides the patient to start SupportScreen by pushing the Touch Here To Begin button.

Items are framed to reflect how most people relate to common problems and challenges of daily life in order to provide a sense of comfort and hope based on patients' ability to solve problems in the past. In this context, SupportScreen identifies specific problems and, importantly, helps determine patients' perception of their ability to manage problems. The number and types of problems and the perceived ability to manage these problems are related to levels of overall distress. Being able to label specific problems in common language in itself can help reduce distress. Patients with a history of poor problem-solving or who believe that they are poor problem-solvers will require additional psychosocial support. ${ }^{19,20}$

\section{The City of Hope Model: Identifying and Summarizing Barriers to Medical Care}

At City of Hope, a process was implemented that can serve as a model for other settings. Consecutive patients seen in the outpatient clinics complete SupportScreen as the standard of care before meeting with the physician. As a result of patients' answers, the system generates 5 potential outputs in real time: 1) a summary report for the physician (printed and/ or electronic); 2) tailored, written educational information for patients; 3 ) personalized resources for patients; 4) criteria-driven referrals to professionals and community-based resources; and 5) individual patient responses recorded into a database for analysis.

The summary report, tailored educational information (e.g., talking with your doctor, fertility), and personalized resources requested (e.g., transportation, finances) are automatically printed immediately after completion of the questions. An e-mail of the summary report is simultaneously sent to the patient's primary care physician and other health care team professionals as indicated. The report is designed for easy identification of problems requiring timely intervention. SupportScreen is modifiable to identify problems or symptoms requiring immediate attention; for example, Thoughts of ending my own life and Pain can be programmed as "hot buttons." This enables the physician to focus on the concerns that are most salient during clinical encounter.

The summary report information is filed in the medical chart and individual patient responses are recorded electronically into a database for analysis. The raw data are available on a secure passwordprotected server and can only be accessed through a Web-based administrative screen. The system can also generate a cumulative report, which includes basic frequencies of 5 categories: 1) patient demographics; 2 ) problems that are distressing (rated $\geq 3$ ); 3) patients who want to Talk with a Member of Team; 4) patients who request Provide Written Information; 


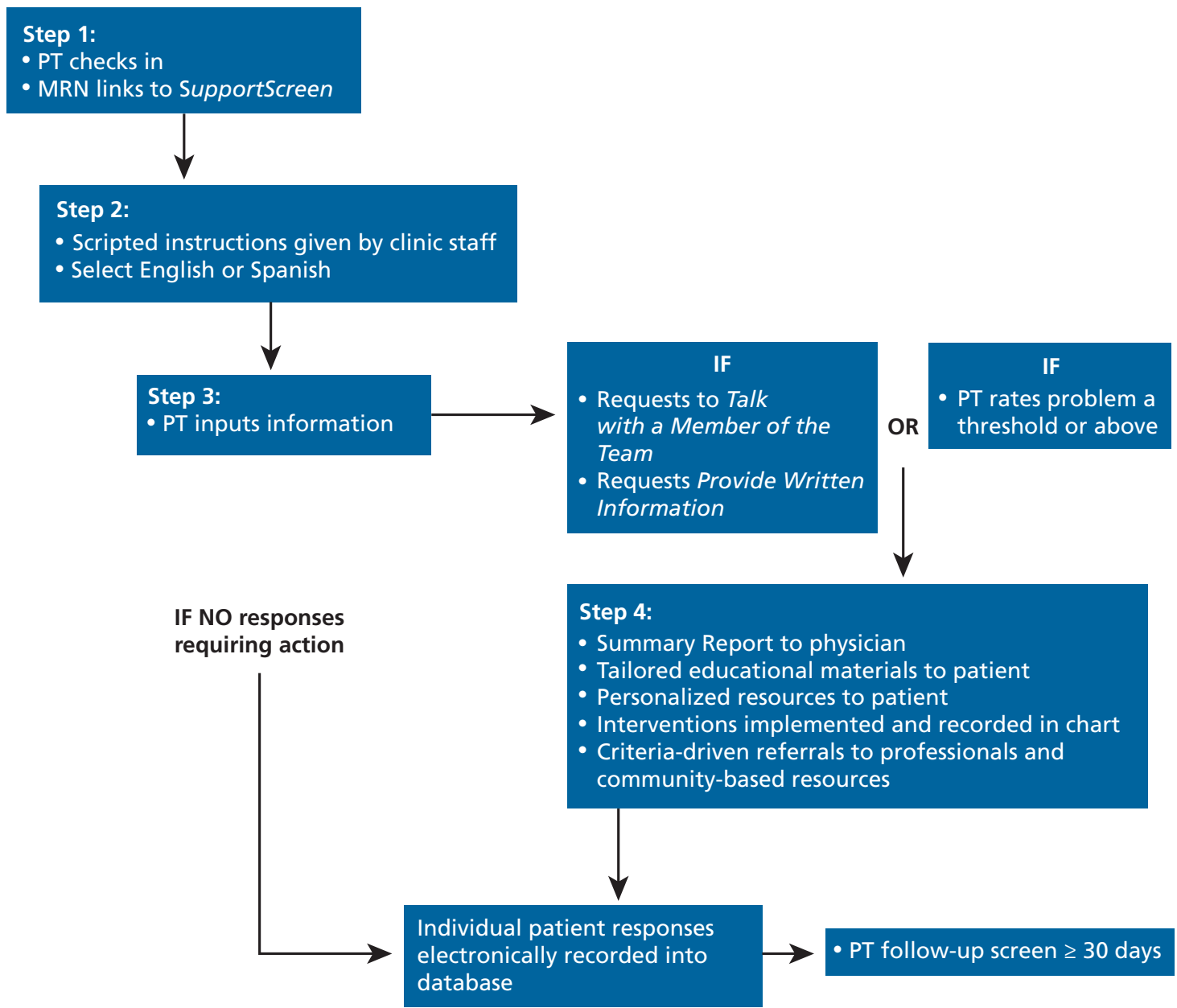

Figure 2 SupportScreen in action.

Abbreviations: MRN, medical record number; PT, patient.

and 5) patients who both want to Talk with a Member of Team and request Provide Written Information.

\section{Using Technology to Enhance Personalized Medical Care}

SupportScreen automates the triage and referral process using criteria determined by the physician and health care team. The primary physician is still able to manage all referrals to consultants whenever necessary. Triage and referral criteria are based on the specific needs of patients, current resources available, and staffing levels. In SupportScreen, each item is precoded and electronically transmitted to a specific professional or resource in real time. In addition, a copy of the notification is sent to the patient's physician, nurse, and social worker to ensure effective ongoing communication.

SupportScreen is designed to be flexible and easily changed to direct the electronic triage and referral information. At City of Hope, the NCCN Clinical Prac- tice Guidelines in Oncology: Distress Management ${ }^{9}$ (in this issue; to view the most recent version of these guidelines, visit the NCCN Web site at www.NCCN. org) are one source of information used to develop the triage, referral, and intervention processes.

Each item on SupportScreen is linked to one or more specific professionals. For example, a pain distress level of 4 or greater is immediately sent to the identified physician, nurse, and social worker. Problems related to physical symptoms such as nausea or recent weight change are referred to a physician and/or nurse. Problems related to emotional, social, and practical concerns, such as Feeling down or depressed or Feeling hopeless, are triaged to a social worker for assessment and potential referral to psychology or psychiatry.

Each designated health professional is copied on all e-mails regarding the patient. This electronic transfer of information helps ensure timely commu- 


\section{Table 2 SupportScreen: Features and Professional Users at City of Hope}

\section{Features of SupportScreen}

Automated Features

Summary Report for physician, printed and electronic Tailored educational written information, printed Personalized resources, printed Interventions implemented and recorded in chart Criteria-driven referrals to professionals and community-based resources

Individual patient responses electronically recorded into a database for analysis

Customized reports (i.e., diagnosis, stage, demographics)

Re-screen alert ( $\geq 30$ days)

Ongoing improvement feedback mechanism for all users

Security Features

Controlled levels of access

Firewall protected

Medical record number encrypted

Patient security: requires medical record number, patient name, and date of birth

Database Features

Clinical research

Data easily exportable

Prepopulated demographic and clinical information

Professional Users

Primary Health Care Team

Physicians

Nurses

Social workers

Consultants

Clinical nutritionists

Cosmetologists

Health educators

Patient navigators

Pain and palliative care team

Psychologists

Psychiatrists

Physical therapists

Pharmacists

Researchers

Spiritual counselors

nication and clear delineation of responsibility for follow-up. This is especially important given the difficulty in maintaining ongoing and consistent com- munication with the number of specialists potentially involved in the patients' care. However, the authors' experience in screening patients with cancer suggests that most requests for assistance relate to educational materials that can be now provided automatically by SupportScreen.

Most triage and referrals do not require immediate attention; these can almost always be addressed within a reasonable time. Additionally, most actions required by SupportScreen are addressed by the psychosocial team and nursing. At City of Hope, only $15 \%$ of the items are triaged to the physician for attention.

\section{A Model for Transprofessional Practice in Patient- Centered Care}

Any biopsychosocial screening process must be tailored to the individual needs of the clinical setting. City of Hope has made elevating whole-patientcentered care part of its strategic plan. The construction of the Sheri \& Les Biller Patient and Family Resource Center (Biller Resource Center) and the creation of the Department of Supportive Care Medicine are manifestations of this commitment. Creating the "best program of supportive care services in the world" is the vision statement for the department.

The Biller Resource Center was started with seed money from philanthropists Sheri and Les Biller. This contribution was based on a long-term commitment by City of Hope to create a comprehensive integrated program of psychosocial and palliative care services. The goal was to unite and integrate compassionate professionals who had expertise in helping patients, families, faculty, and staff to manage the challenges of serious illness and find personal meaning in the experience.

To better focus on the needs of patients, all supportive care services were brought under one departmental infrastructure. Highly interactive relationships with other departments were also built, regardless of administrative governance. All programs and professional interactions are based on the direct and indirect benefits of the clinical, research, and educational programs on patients and families. To ensure improvement and maintain a focus on the mission, systematic program evaluation is at the core of all departmental initiatives.

City of Hope subsequently created the Department of Supportive Care Medicine and recruited a chair to advance the academic foundation for 
Loscalzo et al.

\section{Table 3 SupportScreen 53-Questions Screening Instrument*}

\section{Problems}

- Ability to have children

- Becoming too ill to communicate my choices about medical care

- Being unable to take care of myself

- Bowel movement/constipation

- Controlling my urine or stool

- Eating, chewing, or swallowing difficulties

- Fatigue (feeling tired)

- Fear of medical procedures

- Feeling anxious or fearful

- Feeling down or depressed

- Feeling hopeless

- Feeling irritable or angry

- Feeling isolated, alone, or abandoned

- Finances

- Finding community resources near where I live

- Finding meaning or purpose in my life

- Finding reliable information about complementary or alternative practices

- Getting medicines

- Health insurance

- How my family will cope

- Joint limitations

- Losing control of things that matter to me

- Managing my emotions

- Managing work, school, or home life

- My ability to cope

- Nausea and vomiting

- Needing help coordinating my medical care
- Needing practical help at home

- Pain

- Physical appearance

- Providing care for someone else

- Questions and fear about end of life

- Recent weight change

- Seriously considering taking my own life

- Sexual function

- Side effects of treatments

- Sleeping

- Solving problems because of my illness

- Speech

- Spiritual or religious concerns

- Substance use: you or your environment

- Swelling

- Talking with doctor

- Talking with family, children, and friends

- Talking with the health care team

- Talking with the health care team about use of food/herbal supplements while on treatment

- Thinking clearly

- Tobacco use

- Transportation

- Understanding my treatment options

- Understanding the importance of physical activity even during treatment

- Walking climbing stairs

- Worry about the future

*Items can be added, modified, and/or deleted, and tailored to the individual setting.

the program. The authors believe this patient-centered-rather than profession-centric-paradigm of transprofessional care more accurately reflects the way patients and families experience the need for services.

Patient-centered care is also built into the SupportScreen system at many levels. Although the program can identify problems and link patients to the support and education they need on an individual level, programs are also available to systematically evalutate the patient and family experience at a macro level across the entire health care system. For example, a Patient Advisory Council meets monthly to bring in the patient and family experience to bet- ter-inform programs and processes within the wider hospital system. The Patient Advisory Council is a consistent voice for the patient and family perspective- part focus group and part committed consultants - and has been found to be honest, frank, and helpful. Having patient and family involvement from the beginning, and at this level of detail, has been invaluable to the success of this program.

The Biller Resource Center is also designed to serve as the focal point of whole-patient care. It is strategically located at the center of the hospital's main lobby. Disease and treatment information, education, counseling, advocacy, mental health, palliative care, and spiritual services are all available in 
one place. Navigators, health educators, psychiatrists, psychologists, social workers, palliative care physicians, nurses, spiritual care counselors, cosmetologists, program evaluators, researchers, and volunteers all use the Biller Resource Center as a nexus. It is also a place to learn about and provide consent for clinical trials. In addition, nurses are available to help patients and family members search the Internet to retrieve and interpret scholarly articles. As an added benefit, patients, families, and community members have formed spontaneous, natural support groups while waiting to meet with professionals or search the Internet. The SupportScreen program serves as the connective tissue for these supportive care services.

\section{Conclusions}

Whole-person patient-centered care creates a supportive environment where patients and their families, caregivers, and health care professionals can work together as partners. Because of the everincreasing demands on physician time and heightened expectations of patients and families, health care professionals must use technology to maximize the limited time of the clinical encounter.

Systematic screening automates processes that enhance physician control, efficiency of the clinical encounter, quality of care, patient satisfaction, adherence to treatment, and safety, and makes an essential connection to supportive care services. Automating screening also decreases disruptions to the clinic setting, misuse of physician and staff time, unnecessary suffering of patients and families, and staffrelated distress resulting from the unmet supportive care needs of patients and families.

Based on a history of screening experience in multiple settings, the authors developed SupportScreen to be a model of biopsychosocial screening for whole-patient-centered care, from initiation of patient responses to the generation of referrals and provision of educational information. SupportScreen facilitates patient, physician, and specialist communication and is designed to maximize the effectiveness of clinical encounters and overall cancer care. The program is easily adaptable to a wide variety of clinical settings and has implications for the development of tailored educational programs and for research. The cost of the program depends on the number of licensed sites and users and the extent of the training, support, and other services, but generally ranges from $\$ 15,000$ to $\$ 40,000$ per year.

Therapeutic relationships between patients and their health care providers is being redefined by technology and proposed major changes in the health care system. The speed of technological advances is only expected to increase, but ultimately caring for and healing patients will always be about trusting and respectful relationships. Screening for problems such as distress creates an environment in which communication and unified action leads to a sense of direction and connection that promotes wholepatient-centered care and improved outcomes.

\section{Acknowledgments}

SupportScreen is funded by the City of Hope with special thanks to Alexandra Levine, MD; Sheri and Les Biller; Warren Chandler; and Jay Thomas, MD, $\mathrm{PhD}$, and to all of our colleagues who gave so tirelessly to create the best screening program in the world. Finally, thanks to Drs. Jimmie Holland, James Zabora, and Barry Bultz for their visionary leadership in promoting distress screening as a standard of care for all patients with cancer.

\section{References}

1. Derogatis LR, Morrow GR, Fetting J, et al. The prevalence of psychiatric disorders among cancer patients. JAMA 1983;249:751757.

2. Hegel MT, Moore CP, Collins ED, et al. Distress, psychiatric syndromes, and impairment of function in women with newly diagnosed breast cancer. Cancer 2006;107:2924-2931.

3. Carlson LE, Bultz BD. Benefits of psychosocial oncology care: improved quality of life and medical cost offset. Health Qual Life Outcomes 2003;1:8.

4. Thomas BC, Thomas I, Nandamohan V, et al. Screening for distress can predict loss of follow-up and treatment in cancer patients: results of development and validation of the Distress Inventory for Cancer Version 2. Psychooncology 2009;18:524-533.

5. Kelly C, Ghazi F, Caldwell K. Psychological distress of cancer and clinical trial participation: a review of the literature. Eur J Cancer Care (Engl) 2002;11:6-15.

6. Zabora J, BrintzenhofeSzoc K, Jacobsen P, et al. A new psychosocial screening instrument for use with cancer patients. Psychosomatics 2001;42:241-246.

7. Hoffman BM, Zevon MA, D’Arrigo MC, Cecchini TB. Screening for distress in cancer patients: the NCCN rapid-screening measure. Psychooncology 2004;13:792-799.

8. Sellick SM, Edwardson AD. Screening new cancer patients for psychological distress using the hospital anxiety and depression scale. Psychooncology 2007;16:534-542. 
Loscalzo et al.

9. Holland JC, Andersen B, Breitbart WS, et al. NCCN clinical practice guidelines in oncology: distress management. version 1 , 2010. Available at: http://www.nccn.org/professionals/physician_ gls/PDF/distress.pdf. Accessed January 26, 2010.

10. Institute of Medicine (IOM). Cancer Care for the Whole Patient: Meeting Psychosocial Health Needs. Washington, DC: The National Academies Press; 2007.

11. Chang VT, Hwang SS, Feuerman M. Validation of the Edmonton symptom assessment scale. Cancer 2000;88:2164-2171.

12. Clark KL, Bardwell WA, Arsenault $\mathrm{T}$, et al. Implementing touch screen technology to enhance recognition of distress. Psychooncology 2009;18:822-830.

13. Greenfield S, Kaplan S, Ware J Jr. Expanding patient involvement in care: effects on patients' outcomes. Ann Intern Med 1985;102:520-528.

14. Zabora J, BrintzenhofeSzoc K, Curbow B, et al. The prevalence of psychological distress by cancer site. Psychooncology 2001;10:19_ 28.

15. Zabora JR, Loscalzo MJ, Weber J. Managing complications in cancer: identifying and responding to the patient's perspective. Semin Oncol Nurs 2003;19(4 Suppl 2):1-9.
16. Loscalzo MJ, Clark KL. Problem-related distress in cancer patients drives requests for help: a prospective study. Oncology 2007;21:1133-1138.

17. Clark K, Loscalzo M. How to: Implement Automated Screening for Problem-Related Distress in Cancer Settings [Psycho-oncology (UK) Information \& Help Web site]. Available at: http://www. psycho-oncology.info/PG_automated_clark.pdf. Accessed January 26, 2010.

18. Kincaid JP, Fishburne RP Jr, Rogers RL, Chissom BS. Derivation of new readability formulas (Automated Readability Index, Fog Count and Flesch Reading Ease Formula) for Navy Enlisted Personnel. Millington, TN: U. S. Naval Air Station; 1975. Branch report 8-75.

19. Houts PS, Nezu AM, Nezu CM, Bucher JA. The prepared family caregiver: a problem-solving approach to family caregiver education. Patient Educ Couns 1996;27:63-73.

20. Nezu AM, Nezu CM, Felgoise SH, et al. Project Genesis: assessing the efficacy of problem-solving therapy for distressed adult cancer patients. J Consult Clin Psychol 2003;71:1036-1048. 